\title{
Glucagon-Like Peptide-1 Cleavage Product Improves Cognitive Function in a Mouse Model of Down Syndrome
}

\author{
DStephen M. Day, ${ }^{1,2}$ Wenzhong Yang, ${ }^{1}$ 'Din Wang, ${ }^{1}$ Jennifer E. Stern, ${ }^{1}$ Xueyan Zhou, ${ }^{1}$ Shannon L. \\ Macauley, ${ }^{1}$ and ${ }^{1}$ Tao $\mathrm{Ma}^{1,2,3}$
}

https://doi.org/10.1523/ENEURO.0031-19.2019

\begin{abstract}
${ }^{1}$ Departments of Internal Medicine and Gerontology and Geriatric Medicine, Wake Forest School of Medicine, Winston-Salem, North Carolina 27157, ${ }^{2}$ Department of Integrative Physiology \& Pharmacology, Wake Forest School of Medicine, Winston-Salem, North Carolina 27157, and ${ }^{3}$ Department of Neurobiology and Anatomy, Wake Forest School of Medicine, Winston-Salem, North Carolina 27157
\end{abstract}

\begin{abstract}
Currently there is no effective therapy available for cognitive impairments in Down syndrome (DS), one of the most prevalent forms of intellectual disability in humans associated with the chromosomes 21 trisomy. Glucagon-like peptide-1 (GLP-1) is an incretin hormone that maintains glucose homeostasis by stimulating insulin secretion. Its natural cleavage product GLP-1 (9-36) lacks insulinotropic effects and has a low binding affinity for GLP-1 receptors; thus, GLP-1 (9-36) has historically been identified as an inactive metabolite. Conversely, recent work has demonstrated interesting physiological properties of GLP-1 (9-36) such as cardioprotection and neuroprotection. We have previously shown that GLP-1 (9-36) administration enhances neuronal plasticity in young WT mice and ameliorates cognitive deficits in a mouse model of Alzheimer's disease. Here, we report that systemic administration of GLP-1 (9-36) in Ts65Dn DS model mice of either sex resulted in decreased mitochondrial oxidative stress in hippocampus and improved dendritic spine morphology, increase of mature spines and reduction of immature spines. Importantly, these molecular alterations translated into functional changes in that long-term potentiation failure and cognitive impairments in TsDn65 DS model mice were rescued with GLP-1 (9-36) treatment. We also show that chronic GLP-1 (9-36) treatment did not alter glucose tolerance in either WT or DS model mice. Our findings suggest that GLP-1 (9-36) treatment may have therapeutic potential for DS and other neurodegenerative diseases associated with increased neuronal oxidative stress.
\end{abstract}

Key words: Alzheimer's disease; Down syndrome; GLP-1 (9-36); LTP; oxidative stress; synaptic plasticity

\section{Significance Statement}

Presently no effective treatment exists for cognitive defects in Down syndrome (DS), one of the most common forms of intellectual disability. Here, we studied the effect of the glucagon-like peptide-1 (GLP-1) cleavage product, GLP-1 (9-36), on an established mouse model of DS. We found that GLP-1 (9-36) treatment significantly improved DS-associated memory deficits and synaptic plasticity impairments. Consistently, GLP-1 (9-36) treatment in DS model mice led to decreased levels of mitochondrial reactive oxygen species and improved dendritic spine morphology. Our findings indicate that GLP-1 (9-36) may have therapeutic potential to improve memory and cognition in DS and other neurodegenerative diseases associated with increased neuronal oxidative stress. 


\section{Introduction}

Down syndrome (DS) is one of the most common forms of intellectual disabilities with an apparent genetic cause: the trisomic repeat of chromosome 21 (HSA21; Patterson and Costa, 2005; Mégarbané et al., 2009; Lott and Dierssen, 2010 ). Impaired cognition is a hallmark of DS, and there are currently no effective treatments that improve cognitive function in individuals with DS (Patterson, 2009; Lana-Elola et al., 2011; Lott, 2012). Of note, nearly all DS patients develop typical Alzheimer's disease (AD) neuropathology (i.e., senile plaques and neurofibrillary tangles) by age 40 (Nelson et al., 2011; Head et al., 2016), and many go on to develop age-dependent $A D$ type dementia syndromes later in life (Dierssen, 2012; Zigman, 2013; Bayen et al., 2018).

Increased reactive oxygen species (ROS) is a common feature of many neurologic diseases of cognitive impairment, including DS (Lin and Beal, 2006; Pagano and Castello, 2012; Wang et al., 2014; Guo et al., 2017). Excessive neuronal ROS disrupts molecular and cellular mechanisms underlying memory and synaptic plasticity maintenance and can lead to cognitive impairment (Massaad and Klann, 2011; Guo et al., 2017). Previous studies have demonstrated that decreasing mitochondrial ROS improves memory and hippocampal synaptic plasticity impairments associated with neurodegenerative diseases such as AD (Dumont et al., 2009; Ma et al., 2011; Massaad and Klann, 2011). Therefore, targeting mitochondrial ROS production or clearance may be a feasible strategy to improve cognitive function in individuals with DS.

Glucagon-like peptide-1 (GLP-1) is an incretin hormone released from the L-cells of the distal ileum in response nutrient ingestion. GLP-1 is released into circulation as the "bioactive" GLP-1 (7-36) and has a strong binding affinity to the GLP-1 receptor (GLP1R; Drucker, 2001; Baggio and Drucker, 2007); pancreatic activation of the GLP1R initiates glucose-dependent insulin secretion. Circulating GLP-1 (7-36) is rapidly degraded (half-life $<2$ min) into GLP-1 (9-36) by dipeptidyl peptidase-4 (Deacon et al., 1995; Hansen et al., 1999; Nikolaidis et al., 2005). GLP-1 (9-36) has a low binding affinity to the GLP1R and exerts no insulinotropic effects (Knudsen and Pridal, 1996; Kuc et al., 2014). Thus, GLP-1 (9-36) had been traditionally considered as an "inactive" waste product of GLP-1 (7-36). However, a growing body of evidence indicates that that GLP-1 (9-36) has essential biological func-

Received January 23, 2019; accepted April 2, 2019; First published April 30, 2019.

Author contributions: S.M.D. and T.M. designed research; S.M.D., W.Y., J.E.S., X.Z., and S.L.M. performed research; S.M.D., W.Y., X.W., J.E.S., S.L.M., and T.M. analyzed data; S.M.D. and T.M. wrote the paper.

The authors declare no competing financial interests.

This work was supported by National Institutes of Health Grants R01 AG055581, R01 AG056622 (T.M.), the Alzheimer's Association grant NIRG-15362799 (T.M.), and the BrightFocus Foundation Grant A2017457S.

Correspondence should be addressed to Tao Ma at Tma@wakehealth.edu. https://doi.org/10.1523/ENEURO.0031-19.2019

Copyright (C) 2019 Day et al.

This is an open-access article distributed under the terms of the Creative Commons Attribution 4.0 International license, which permits unrestricted use, distribution and reproduction in any medium provided that the original work is properly attributed. tions separate from its precursor. For example, in human aortic endothelial cells GLP-1 (9-36), not GLP-1 (7-36), reversed high glucose and high free fatty acid-induced ROS production (Giacco et al., 2015). GLP-1 (9-36) also protected Glp1r-/- cardiomyocytes from $\mathrm{H}_{2} \mathrm{O}_{2}$-induced cell death while GLP-1 (7-36) did not (Ban et al., 2010). These data suggest that GLP-1 (9-36) may operate via a mechanism distinct from GLP-1 (7-36). Furthermore, we have shown that GLP-1 (9-36) treatment decreased high levels of hippocampal ROS and rescued memory deficits in a mouse model of AD (Ma et al., 2012). Recently, we demonstrated that chronic GLP-1 (9-36) treatment enhances hippocampal long-term potentiation (LTP) in young WT mice (Day et al., 2017).

In the current study, we aim to investigate whether GLP-1 (9-36) treatment can improve DS pathophysiology by administrating GLP-1 (9-36) systemically to a mouse model of DS. A series of experiments were conducted to test effects and relevant cellular/molecular mechanisms of GLP-1 (9-36) treatment on cognitive impairments and synaptic plasticity deficiency in Ts65Dn DS model mice. Our findings suggest that GLP-1 (9-36) may be a novel therapeutic agent in treating DS-associated cognitive dysfunction and synaptic failure.

\section{Materials and Methods}

\section{Animals}

All mice were housed in the Transgenic Mouse Facility at Wake Forest School of Medicine Animal Facility. Mice were kept in compliance with the National Institute of Health (NIH) Guide for Care and Use of Laboratory Animals. The facility kept a $12 \mathrm{~h}$ light/dark cycle with regular feeding, cage cleaning, and $24 \mathrm{~h}$ access to water. Breeder mice were purchased from The Jackson Laboratory. The mouse colony was maintained by breeding Ts65Dn trisomic females (005252) with B6EiC3Sn.BliAF1 males (003647). Ts65Dn mice used in behavioral experiments did not carry the phosphodiesterase $6 b$ (Pde6b) gene mutation associated with retinal degeneration. Genotyping was determined by PCR. All experiments were conducted on male and female 9-month-old mice; Ts65Dn mice reliably exhibit cognitive impairments at this age based on our observation and previous report (Faizi et al., 2011).

\section{GLP-1 (9-36) treatment}

GLP-1(9-36) peptide (Eurogentec) was administered daily via intraperitoneal injection at a dose of $500 \mathrm{ng} / \mathrm{g} / \mathrm{d}$ (Ma et al., 2012). Mice were treated with GLP-1 (9-36) or a saline control for $14 \mathrm{~d}$ before behavioral tests began. GLP-1 (9-36) or saline treatment continued throughout behavioral experiments. Mice were then sacrificed for MitoSOX assay, Golgi-Cox staining, Western blot, or electrophysiological experiments. Mice were weighed weekly to determine appropriate drug dose. GLP-1 (9-36) was prepared as stock solution and was diluted to the final concentrations before use. 


\section{Detection of mitochondrial superoxide in hippocampal slices}

After completion of either drug or vehicle treatment, mice were killed and $400 \mu \mathrm{m}$ hippocampal slices were incubated with $5 \mu \mathrm{M}$ MitoSOX Red, a mitochondrial superoxide indicator (prepared as $5 \mathrm{~mm}$ stock solution immediately before the experiments; Invitrogen) for $10 \mathrm{~min}$. Slices then were fixed with ice-cold $4 \%$ paraformaldehyde in PBS overnight at $4^{\circ} \mathrm{C}$. Slices were further cut into $40 \mu \mathrm{m}$ sections and mounted onto pre-subbed slides with VECTASHIELD mounting medium with DAPI (Vector Laboratories). The sections were imaged using a Leica TCS SP5 confocal microscope at $20 \times$ magnification. All parameters (pinhole, contrast, gain, offset) were held constant for all sections from the same experiment.

\section{Western blot}

Hippocampal slices were flash-frozen on dry ice and sonicated as previously described (Ma et al., 2012). Samples containing equal amounts of protein lysate were loaded on 4-12\% Tris-glycine SDS-PAGE gels for standard gel electrophoresis. Membranes were probed overnight at $4^{\circ} \mathrm{C}$ using the OXPHOS primary antibody (1:250; Abcam) and GAPDH (1:10,000; Cell Signaling). Densitometric analysis was performed using ImageJ software. Data were normalized to GAPDH.

\section{Golgi-Cox stain}

Brains were processed using the FD Rapid GolgiStain Kit in accordance with the manufacturer's instructions (FD Neurotechnologies; catalog \#PK401). Transverse sections (125 $\mu \mathrm{m})$ were made using a Leica VT1200S vibratome and mounted unto gelatin-coated slides. Development was performed according to kit instructions. Sections were dehydrated through a graded ethanol series and cleared in xylene. Slides were cover-slipped with Vectamount Permanent Mounting Medium (Vector Laboratories; catalog, \#H-5000) and imaged at 100X on a Keyence BZ-X710 microscope. For spine analysis, images were blinded, and spines were manually counted and sorted as previously described (Risher et al., 2014).

\section{Glucose tolerance test}

An intraperitoneal glucose tolerance test (IPGTT) was administered to mice before the treatment regimen began and after daily saline or GLP-1 (9-36) treatment (500 $\mathrm{ng} / \mathrm{g} / \mathrm{d})$. On the day of the experiment, mice were fasted for $4 \mathrm{~h}$ and glucose $(2.0 \mathrm{~g} / \mathrm{kg})$ was administered intraperitoneally. Blood samples were taken from tail veins and blood glucose was measured $(0,15,30,45,60,90,120$ min, respectively) using a glucometer (Bound Tree Medical Precision XTRA Glucometer; Fisher).

\section{Hippocampal slice preparation and electrophysiology}

Acute $400 \mu \mathrm{m}$ transverse hippocampal slices were prepared using a Leica VT1200S vibratome as described previously. Slices were maintained at room temperature for at least $2 \mathrm{~h}$ in an artificial CSF containing the following (in $\mathrm{mm}$ ): $118 \mathrm{NaCl}, 3.5 \mathrm{KCl}, 2.5 \mathrm{CaCl}_{2}, 1.3 \mathrm{MgSO}_{4}, 1.25 \mathrm{NaH}_{2} \mathrm{PO}_{4}$, and 15 glucose, bubbled with $95 \% \mathrm{O}_{2} / 5 \% \mathrm{CO}_{2}$. For electrophys- iology, monophasic constant-current stimuli $(100 \mu \mathrm{s})$ were delivered with a bipolar silver electrode placed in the stratum radiatum of area CA3. Field EPSPs (fEPSPs) were recorded using a glass microelectrode from the stratum radiatum of area CA1. LTP was induced using a high-frequency stimulation (HFS) protocol consisting of two $1 \mathrm{~s}, 100 \mathrm{~Hz}$ trains separated by $60 \mathrm{~s}$. Paired-pulse facilitation (PPF) was conducted using a pair of stimuli with interstimulus intervals (ISIs) of $25,50,100,200$, or 300 ms delivered to the CA3, and the respective slopes of the fEPSP were measured. The ratio of the second slope to the first slope, compared with the ISI was plotted. For input/output (I/O) curves, the slopes of fEPSPs and the values of the fiber volley at different stimulation intensities were measured.

\section{Object location memory task}

Mice were habituated to an opaque plastic chamber $(30 \times 21 \times 15 \mathrm{~cm})$ with visible spatial cues for $10 \mathrm{~min}$. After $24 \mathrm{~h}$, mice were returned to the chamber with two identical objects in the arena and were allowed to freely explore and interact with the objects for $10 \mathrm{~min}$. Twentyfour hours later, mice were returned to the chamber again, where one of the two objects had been relocated to an adjacent position (Fig. 1A). Objects and changes in object location were randomly determined and counterbalanced. Time spent with each object was measured and calculated as a percentage of the total object interaction time. Novel object preference of $<50 \%$ indicates memory impairments. Time with objects was measured both manually and with EthoVision XT tracking software. Mice with a total object interaction time of $<10 \mathrm{~s}$ were excluded from analysis. Data collection and analysis were performed blinded.

\section{Passive avoidance task}

For the training phase of the passive avoidance task (PAR apparatus, Panlab), mice were placed in a well-lit chamber $(25 \times 25 \times 24 \mathrm{~cm})$. Following a $60 \mathrm{~s}$ exploration period a trap door opened to reveal a smaller, dark chamber $(19 \times 10 \times 12 \mathrm{~cm})$. On entry into the dark chamber the trap door closed, and mice were given a mild foot shock (foot shock intensity: $0.1 \mathrm{~mA}, 2 \mathrm{~s}$ duration). Memory was tested $24 \mathrm{~h}$ after training when mice were returned to the light chamber, and following a $60 \mathrm{~s}$ exploration period, the trap door opened to reveal the dark chamber. On entry into the dark chamber the trap door closed (no foot shock was given on the test day). For training and test day, mice were given a max latency of $600 \mathrm{~s}$. Mice that did not enter the dark chamber on the first day were not included in data analysis.

\section{Data analysis}

Data were presented as mean \pm SEM. Summary data are presented as group means with SE bars. Normality of the data were tested using GraphPad Prism (GraphPad Software), and the criteria for parametric testing were met. For comparisons between two groups, a two-tailed independent Student's $t$ test was performed using GraphPad Prism 7 software. Two-tailed unpaired $t$ tests were performed for within-group analyses. For comparisons between more than two groups, two-way repeated mea- 
A

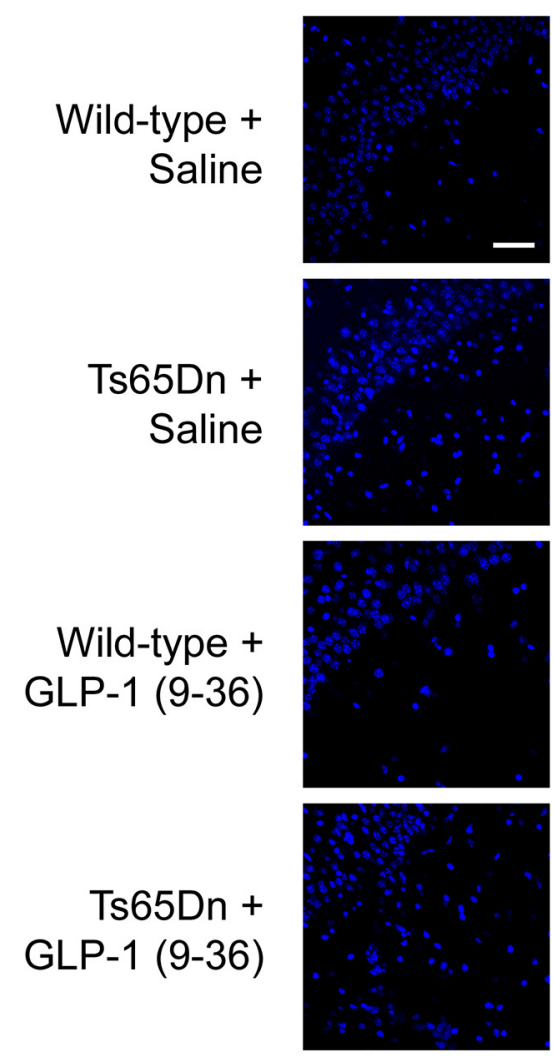

MitoSOX
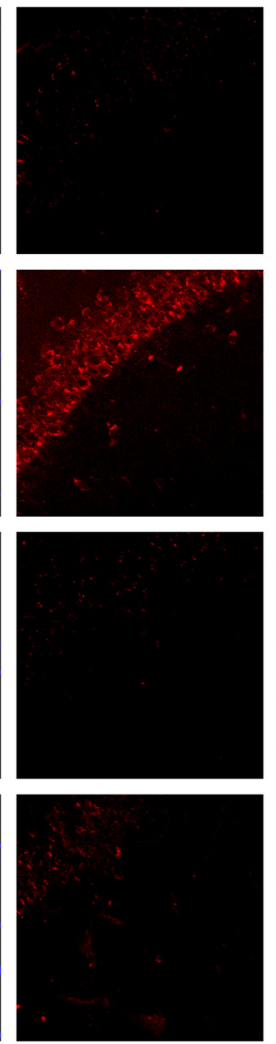

Merged
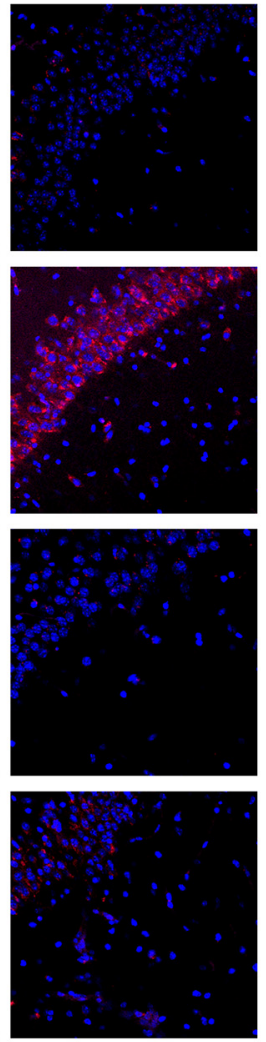

B Complex I Complex II Complex III
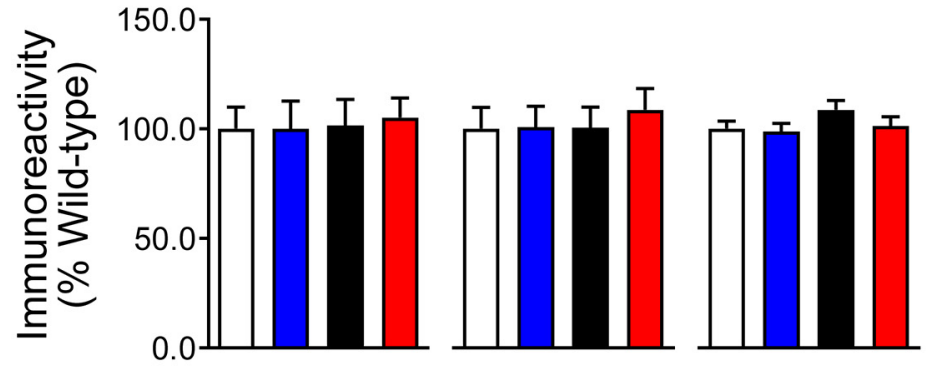

$\square$ Wild-type + Saline

- Ts65Dn + Saline

Wild-type + GLP-1 (9-36)

$\square$ Ts65Dn + GLP-1 (9-36)
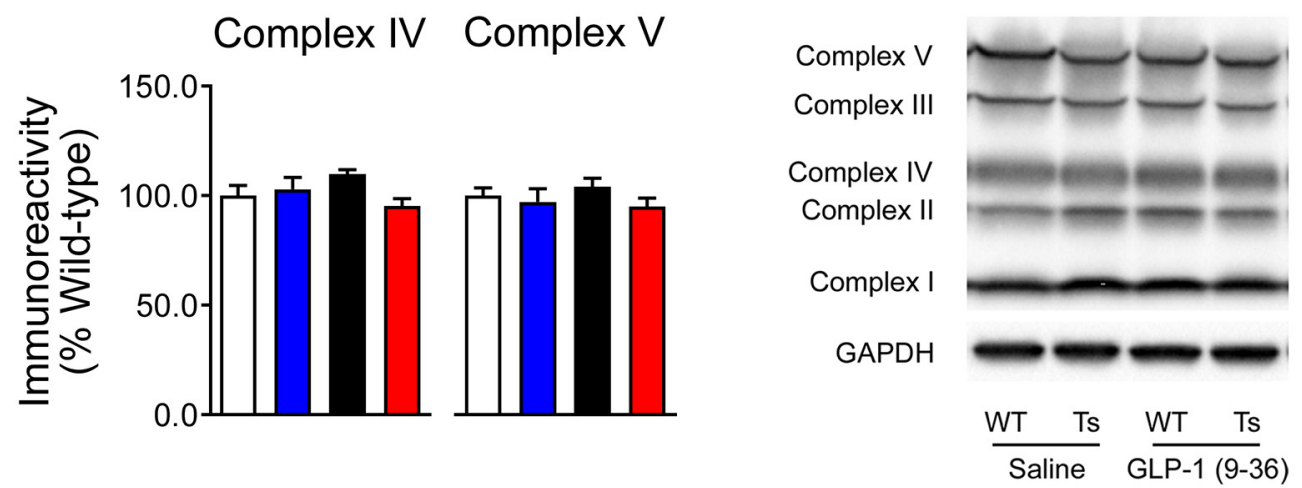

Figure 1. GLP-1 (9-36) treatment normalizes increased hippocampal mitochondrial superoxide in Ts65Dn mice. A, The MitoSOX fluorescent signal (red) was increased in area CA1 of hippocampal slices from Ts65Dn compared with slices from WT mice. GLP-1 (9-36) treatment normalized the DS-associated increased fluorescent signal. Results are representative of three independent 
continued

experiments (20×, scale bar, $50 \mu \mathrm{m} ; n=3$ per group). $\boldsymbol{B}$, Western blot experiment revealed no significant difference in the expression of oxidative phosphorylation complex proteins among all four experimental groups ( $n=8$ per group).

sures ANOVA was used with Tukey's post hoc tests for multiple comparisons. Error probabilities of $p<0.05$ were considered statistically significant.

\section{Experimental design and statistical analysis}

All statistical comparisons were done in four mouse groups: WT + saline, Ts65Dn + saline, WT + GLP-1 (9-36), and Ts65Dn + GLP-1 (9-36). The number of mice ( $n$ ) for each comparison is given in the corresponding figure legends. For each tested parameter, data distributions are represented by mean $\pm \mathrm{SEM}$. For all tests, results were considered statistically significant at $p<0.05$. All data analyses and statistics were performed in GraphPad Prism (GraphPad Software).

\section{Study approval}

All methods involving animals were approved by the IACUC of Wake Forest University School of Medicine.

\section{Results}

\section{GLP-1 (9-36) treatment decreases DS-associated elevated levels of mitochondrial superoxide}

Increased neuronal mitochondria-derived ROS is an important feature of DS and is linked to cognitive impairments (Massaad and Klann, 2011; Zis et al., 2012). Previous studies have demonstrated that GLP-1 (9-36) treatment decreases ROS production both in cultured cells and animal models (Ban et al., 2010; Ma et al., 2012; Giacco et al., 2015). To determine whether GLP-1 (9-36) treatment is able to decrease DS-associated ROS, we assessed the levels of mitochondrial ROS by staining live slices with MitoSOX Red, a fluorogenic dye that selectively detects mitochondria-specific superoxide, a primary ROS (Ma et al., 2012; Wong et al., 2015; Ishii et al., 2017). Compared with WT mice, Ts65Dn mice demonstrated significantly enhanced MitoSOX fluorescence signal, indicating increased levels of mitochondrial superoxide and ROS (Fig. 1A). Notably, GLP-1 (9-36) treatment blunted the DS-associated increase in mitochondrial superoxide (Fig. 1A). We further examined the effects of GLP-1 (9-36) treatment on mitochondrial electron transport chain (ETC) proteins using Western blot assay. The ETC consists of a series of protein complexes that transfer electrons from electron donors to electron acceptors via redox reactions. The ETC proteins create the proton gradient that drives ATP production; however, ETC complexes I and III produce large amounts of superoxide in this process (Massaad and Klann, 2011). We observed no differences in ETC expression according to either genotype or treatment condition (Fig. 1B), indicating that the difference in superoxide production was not because of dysregulations of ETC proteins expression. These findings are also consistent with previous reports demonstrating that GLP-1 (936) has antioxidant-like properties (Giacco et al., 2015).

\section{GLP-1 (9-36) treatment improves dendritic spine morphology in Ts65Dn mice}

Dendritic spine morphology regulation is vital to synaptic integrity and associated with neural plasticity and memory formation (Hering and Sheng, 2001; Sala and Segal, 2014). Excessive ROS can also affect regulation of spine morphology (Dos Reis et al., 2013). Using the rapid Golgi-Cox staining protocol, we assessed spine density and morphology changes of dendritic spines within the stratum radiatum of hippocampal CA1 area. Although there were no differences in overall dendritic spine density between groups (Fig. 2A,B), we further analyzed changes in spine morphology based on published guidelines ("mature" vs "immature"; Fig. 2C; Risher et al., 2014), and found significant morphologic differences. Compared with WT mice, Ts65Dn mice showed a significantly lower density of mature spines (WT + saline vs Ts65Dn + saline: $p=0.0014)$ and a significantly higher density of immature spines (WT+ saline vs Ts65Dn + saline: $p=0.0013$; WT + GLP-1 (9-36) vs Ts65Dn + saline: $p=0.0016$; Fig. $2 C-E$ ). Markedly, GLP-1 (9-36) treatment restored spine morphology (both mature and immature) in Ts65Dn mice to WT norms (Fig. 2D-E). These differences in spine morphology became apparent when we calculated the mature/immature spine ratio for each group. We found that saline- and GLP-1 (9-36)-treated WT mice had a significantly higher mature/immature spine ratio than salinetreated Ts65Dn mice (WT + saline vs Ts65Dn + saline: $p$ $=0.0155$; WT + GLP-1 (9-36) vs Ts65Dn + saline: $p=$ 0.0222; Fig. 2F). Importantly, Ts65Dn mice treated with GLP-1(9-36) had a significantly higher mature-immature spine ratio than Ts65Dn mice treated with saline $(p<$ 0.0001; Fig. 2F). Furthermore, we characterized and quantified each individual category of the spine data (Fig. $2 G, H)$. Of interest, for branched mature and filopodia immature spines, we did not observe any significant DSassociated alternations or rescuing effects of GLP-1 (936) (Fig. 2G,H). Together, these data indicate beneficial effects of GLP-1 (9-36) treatment on DS-associated impairments of synaptic structure, which may represent a mechanism through which GLP-1 (9-36) improves cognition and synaptic function.

\section{GLP-1 (9-36) treatment does not affect glucose clearance in Ts65Dn or WT mice}

GLP-1 (7-36), the precursor peptide of GLP-1(9-36), is known as an insulinotropic hormone; it enhances insulin secretion and promotes glucose clearance in humans. In contrast, GLP-1 (9-36) has low binding affinity for the GLP-1R and usually is not considered to have any insulinotropic effects (Vahl et al., 2003). Nevertheless, given that we are treating mice with GLP-1 (9-36) at supraphysiological doses, we sought to determine whether GLP-1 (9-36) affects glucose tolerance at the dose administered. To measure this, we performed an IPGTT (Macklin et al., 
A

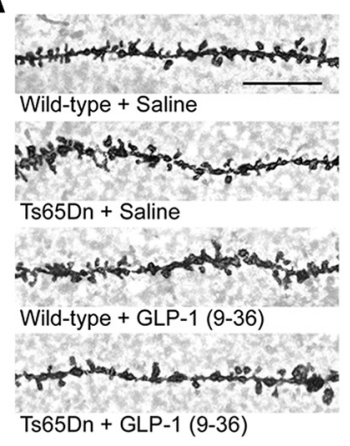

D

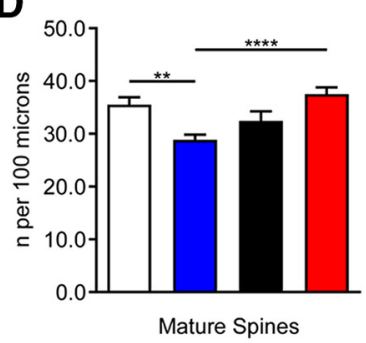

B

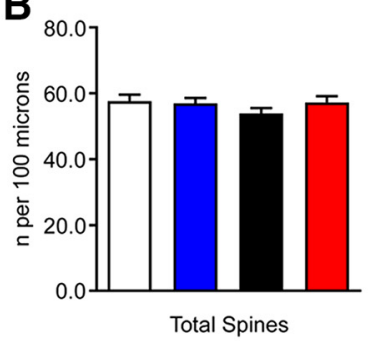

$\mathbf{E}$

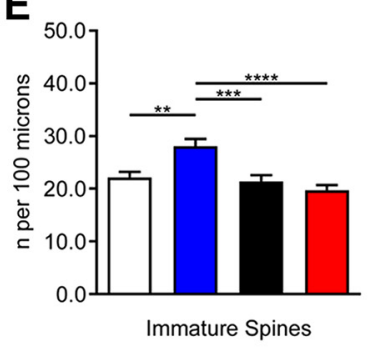

C

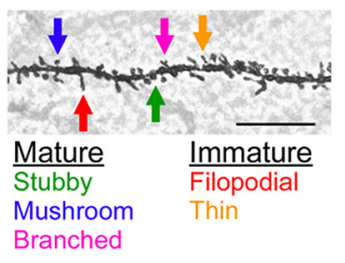

$\mathbf{F}$

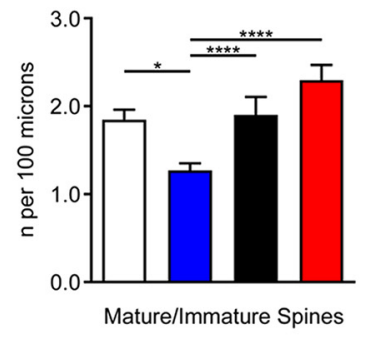

\section{G}

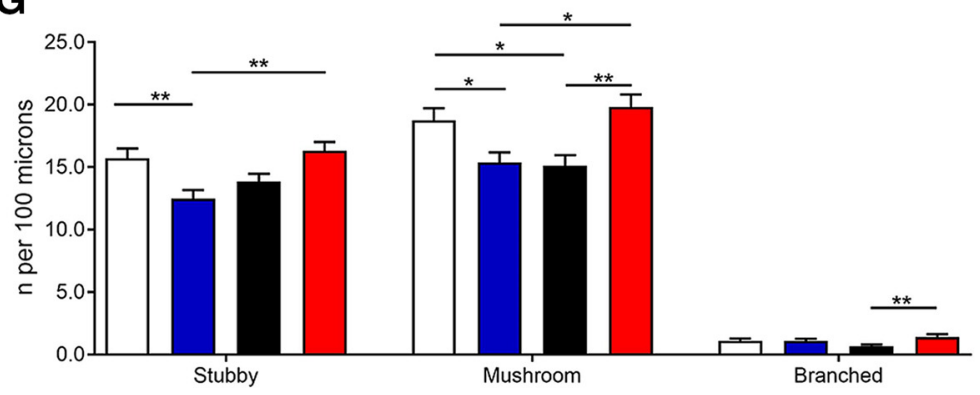

H

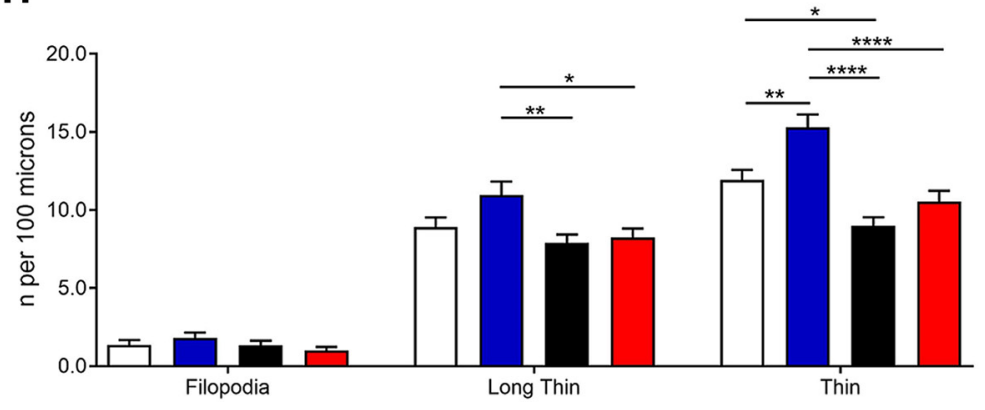

Figure 2. GLP-1 (9-36) treatment improves dendritic spine morphology of hippocampus in Ts65Dn mice. $\boldsymbol{A}$, Representative images from Golgi-Cox stain of area CA1 dendritic spines (100×, scale bar, $12.5 \mu \mathrm{m}$ ). $\boldsymbol{B}$, Total area CA1 dendritic spine density (counts per $100 \mu \mathrm{m})$ was unaltered among all experimental groups. $\boldsymbol{C}$, Diagram depicting dendritic spine classification based on previous publication (100 $\times$, scale bar, $12.5 \mu \mathrm{m}$ ). $\boldsymbol{D}$, Mature spine density (counts per $100 \mu \mathrm{m}$ ) was decreased in Ts65Dn mice compared with WT group, and was improved with treatment of GLP-1 (9-36). Stubby, mushroom, and branched spine types were classified as mature. $E$, Immature spine density (counts per $100 \mu \mathrm{m}$ ) was increased in Ts65Dn mice compared with WT group, and was restored with GLP-1 (9-36) treatment. Filopodial and thin type spies were classified as immature. $\boldsymbol{F}$, Mature-immature spine ratio was reduced in Ts65Dn mice compared with WT group, and was restored with GLP-1 (9-36) treatment. G, Subclassification of mature spines. $\boldsymbol{H}$, Subclassification of immature spines (WT+ Saline: $n=81$ dendrites; Ts65D + Saline; $n=80$ dendrites; WT + GLP-1 (9-36): $n=51$ dendrites: Ts65D + GLP-1 (9-36): $n=81$ dendrites). * $<<0.05$, $* * p<0.01, * * * p<0.001, * * * * p<0.0001$; one-way ANOVA with Tukey's posthoc test. Values represent mean \pm SEM.

2017). As shown in Figure 3, saline or GLP-1 (9-36) treatment did not alter glucose tolerance in both WT and Ts65Dn mice, as indicated by measurement of the glucose $\mathrm{x}$ time clearance curve and the area under the curve (AUC; Fig. 3A-H).

\section{GLP-1 (9-36) treatment rescues hippocampal} synaptic plasticity impairments in Ts65Dn mice

Previous studies revealed hippocampal synaptic plasticity impairments in Ts65Dn mice (Kleschevnikov et al., 2004; Costa and Scott-McKean, 2013). We next 
Wild-type + Saline
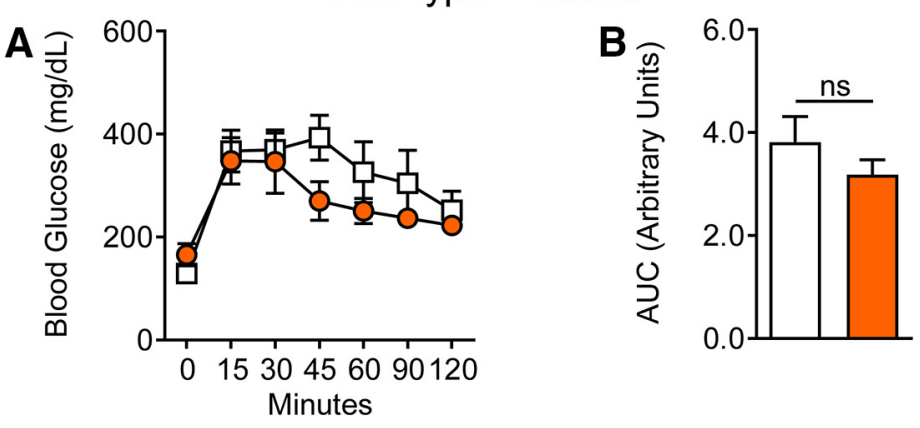

Ts65Dn + Saline
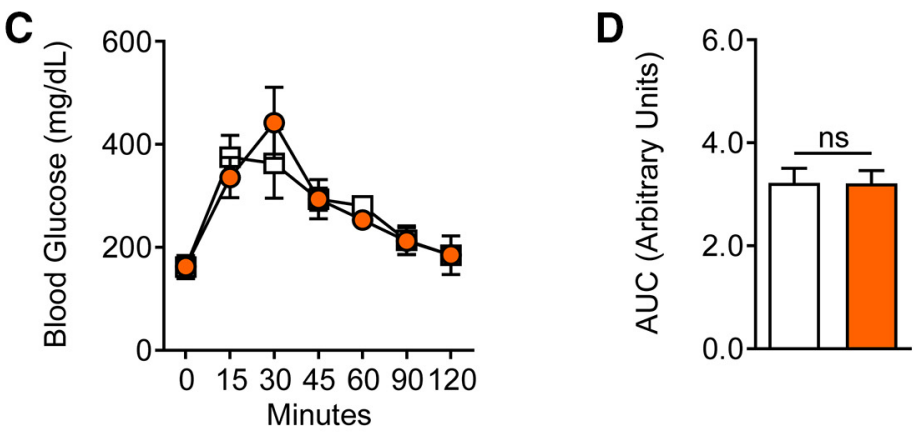

Wild-type + GLP-1 (9-36)
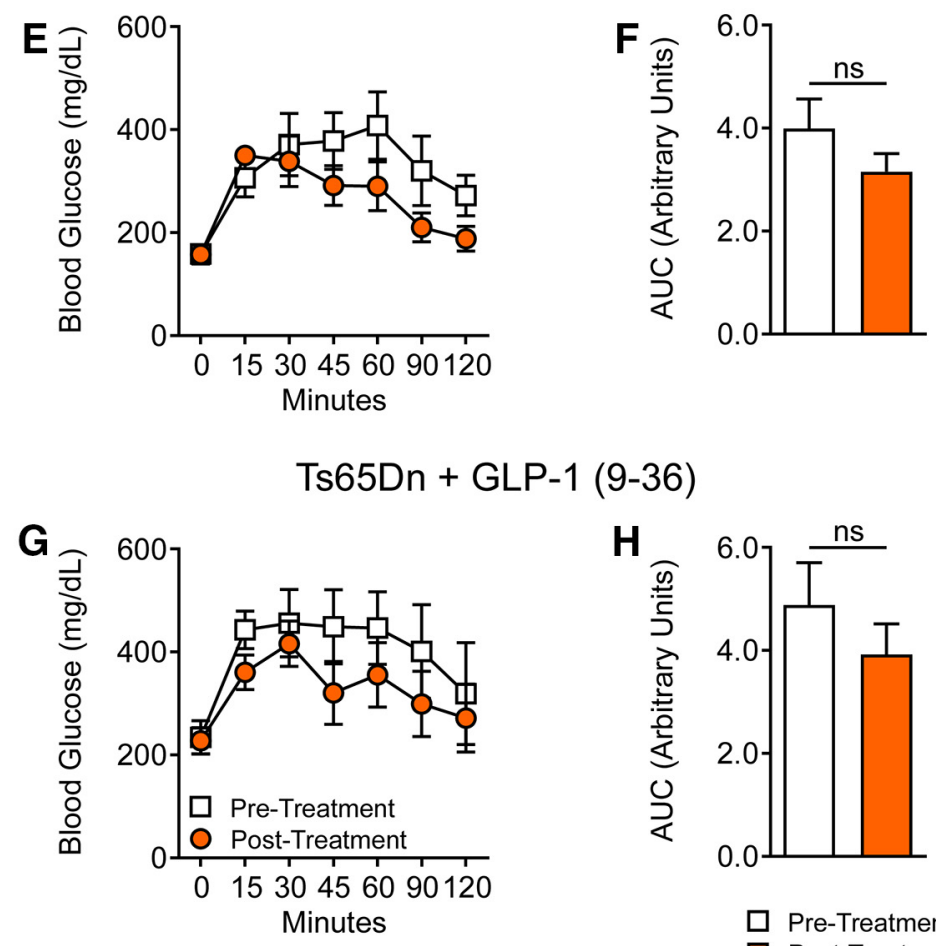

$(9-36)$

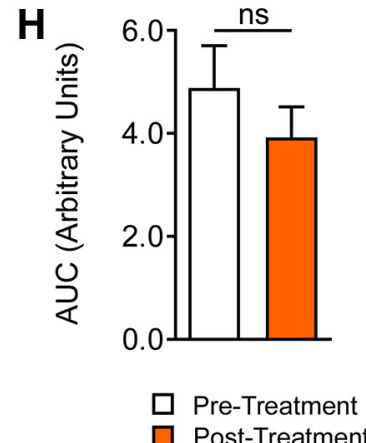

Figure 3. GLP-1 (9-36) treatment does not affect glucose clearance following glucose tolerance tests. Glucose tolerance test (GTT) of WT and Ts65Dn mice was performed before and after saline or GLP-1 (9-36) treatments. A, C, $\boldsymbol{E}$, G, Two-way ANOVA revealed no significant differences between pretreatment or post-treatment in glucose response curves among all four experimental groups. $\boldsymbol{B}$, $\boldsymbol{D}, \boldsymbol{F}, \boldsymbol{H}$, Independent $t$ test revealed no significant differences between pretreatment or posttreatment GTT AUC. WT + Saline: $n=$ 6; Ts65Dn + Saline: $n=5$; WT + GLP-1 (9-36): $n=8$; Ts65Dn + GLP-1 (9-36): $n=6$. 
A

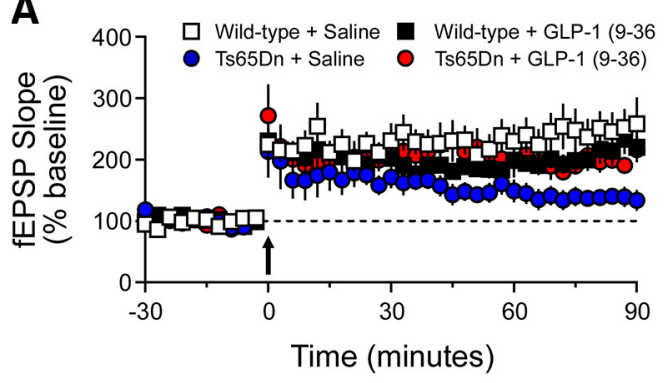

B

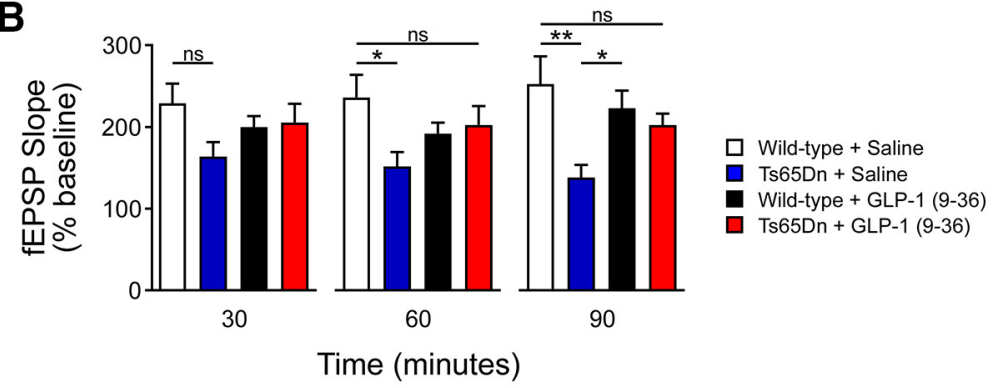

C

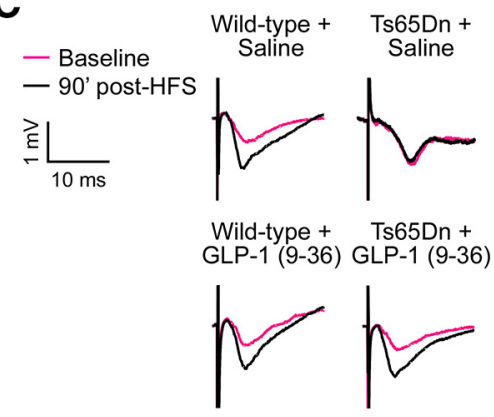

D

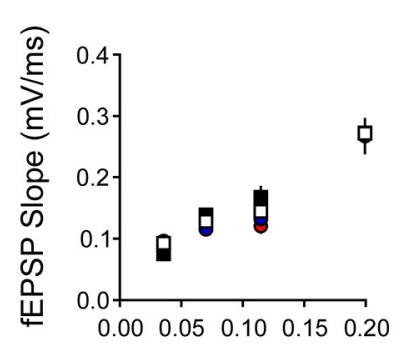

Fiber Volley Amplitude (mV)
E

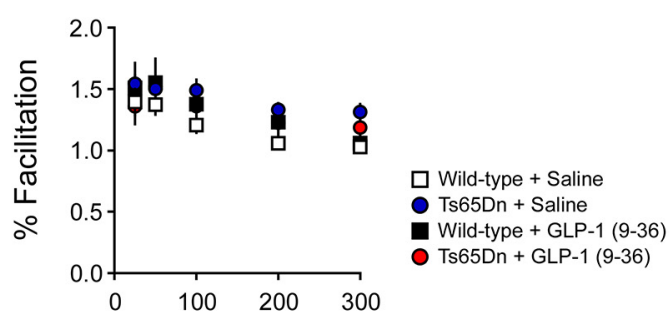

Interstimulus Inteval (ms)

Figure 4. GLP-1 (9-36) treatment rescues hippocampal synaptic plasticity impairments in Ts65Dn mice. $\boldsymbol{A}$, Acute hippocampal slices from WT + Saline $(n=9)$, Ts65Dn + Saline $(n=10)$, WT+ GLP-1 (9-36) $(n=10)$, and Ts65Dn + GLP-1 (9-36) $(n=9)$ mice were stimulated with HFS to induce LTP at the CA3-CA1 synapse. Arrow indicates HFS. Two-way repeated-measures ANOVA revealed significant group $(p<0.05)$, time $(p<0.05)$, and group $\times$ time $(p<0.001)$ effects. At 90 min post-HFS, Tukey's post hoc tests revealed Ts65Dn + Saline had significantly impaired LTP compared with GLP-1 (9-36)-treated Ts65Dn mice $(p<0.05)$ and saline- and GLP-1 (9-36)-treated WT mice $(p<0.001, p<0.05)$. B, Measurement of fEPSP slope at 30, 60, and 90 min after HFS $(* p<0.05, * * p<0.01)$. $\boldsymbol{C}$, Representative fEPSP traces at baseline and 90 min post-HFS. $\boldsymbol{D}$, I/O curves were established by plotting fEPSP amplitudes against fiber volley amplitudes at increasing stimulus intensities in hippocampal slices from WT+ Saline $(n=9)$, Ts65Dn + Saline $(n=10)$, WT + GLP-1 (9-36) $(n=9)$, and Ts65Dn + GLP-1 (9-36) ( $n=9)$ mice. One-way ANOVA revealed no significant differences between groups at any time point. $\boldsymbol{E}$, PPF in WT + Saline $(n=9)$, Ts65Dn + Saline $(n=10)$, WT+ GLP-1 (9-36) $(n=9)$, and Ts65Dn + GLP-1 (9-36) $(n=9)$ mice. One-way ANOVA revealed no significant differences between groups at any time point.

performed electrophysiological experiments to determine whether GLP-1 (9-36) treatment could improve DS-associated deficits of LTP, an established form of synaptic plasticity and a cellular model for learning and memory (Klann and Dever, 2004; Kandel et al., 2014). Although WT mice from both treatment groups [saline and GLP-1(9-36)] showed robust, sustained LTP induced by HFS, saline-treated Ts65Dn mice exhibited declined LTP (Fig. 4 A-C). Of note, LTP impairments in DS mice were significantly rescued by treatment with GLP-1 (9-36) (Fig. 4 A-C). GLP-1 (9-36) "appears" to have depressing but nevertheless insignificant effects on LTP of WT slices (Fig. 4A,B). In addition, we assessed the effects of GLP-1 (9-36) treatment on basal synaptic transmission by inducing synaptic responses with a range of stimulus intensities, and observed similar synaptic I/O relationship among all groups (Fig. 4D). We also investigated PPF, a form of calcium-dependent presynaptic plasticity evoked by two temporally-linked stimuli at various intervals (Katz and Miledi, 1968), and did not find any differences in PPF among all four experimental groups (Fig. 4E). These findings indicate that GLP-1 (9-36) can improve DS-associated synaptic plasticity impairments without affecting basal synaptic transmission.

\section{GLP-1 (9-36) treatment alleviates cognitive deficits in Ts65Dn mice}

To determine whether GLP-1 (9-36) treatment can rescue DS-associated cognitive deficits, we treated Ts65Dn mice and their WT littermates with GLP-1 (9-36) (500 $\mathrm{ng} / \mathrm{g} / \mathrm{d}$; i.p.) or a saline control continuously for $14 \mathrm{~d}$ (Day et al., 2017). We then subjected mice to a series of behavioral tasks to evaluate their cognitive performance. We assessed the spatial learning and memory by testing the mice on object location memory (OLM) task (Kleschevnikov et al., 2012). In the OLM test, WT mice treated with either saline or GLP-1 (9-36) exhibited normal cognition, spending a significantly greater percentage of time interacting with the relocated object than with the object in the old location (Fig. 5A,B). In contrast, Ts65Dn mice treated with saline failed to recognize the relocated object and spent similar amounts of time with either object, indicating impaired spatial learning and memory. Notably, Ts65Dn mice treated with GLP-1 (9-36) displayed normal cognition, as indicated by a preference for objects in the novel location (Fig. 5B).

Moreover, we assessed whether GLP-1 (9-36) treatment would affect long-term associative memory using a 2 d passive avoidance paradigm (Shi and Sun, 2012; Fig. $5 C)$. During the acquisition phase (Day 1 ), mice received a 
A

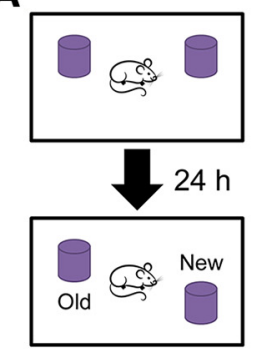

C

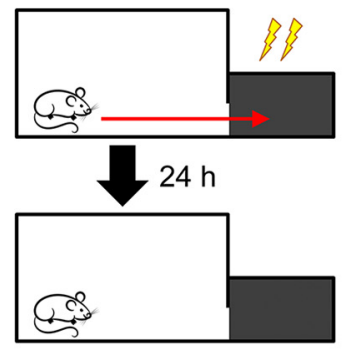

B

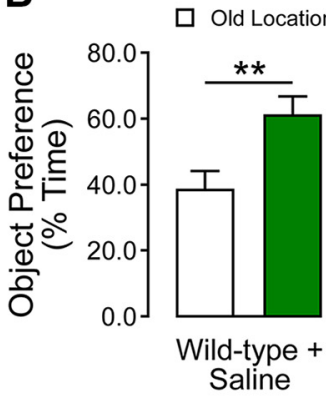

$\square$ New Location
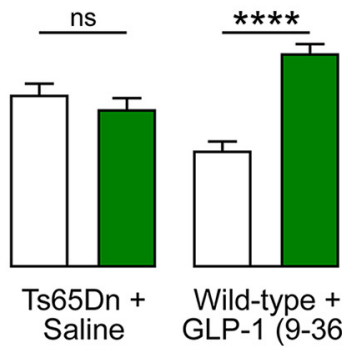

Wild-type + GLP-1 (9-36)

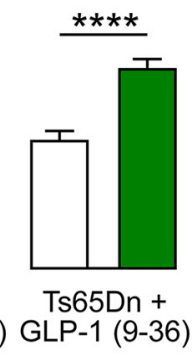

D
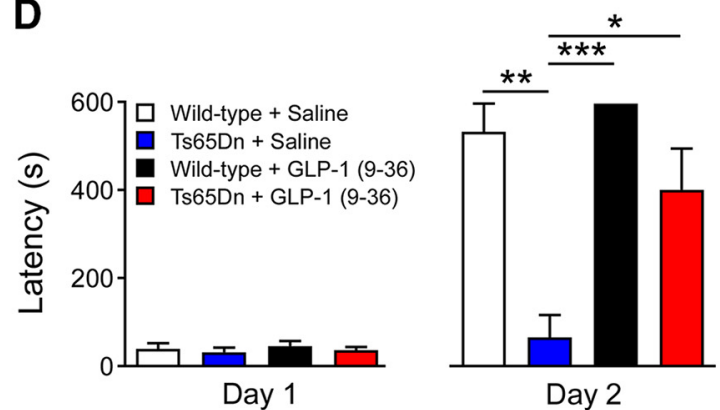

Day 2

Figure 5. GLP-1 (9-36) treatment alleviates cognitive deficits in Ts65Dn mice. A, Schematic of OLM task and object preference for familiar and new locations during the test session. $\boldsymbol{B}$, Spatial memory was impaired in Ts65Dn mice compared with WT controls, and the impairments were rescued with GLP-1 (9-36) treatment. Preference for the new location $<50 \%$ of the total interaction time indicates cognitive impairment (WT + Saline: $n=10$; Ts65Dn + Saline: $n=11$; WT+ GLP-1 (9-36): $n=12$; Ts65Dn + GLP-1 (9-36): $n=13$; **p $<0.01$, *** $p<0.001$, independent $t$ test). $\mathbf{C}$, Schematic of passive avoidance paradigm and latency to dark compartment on Day 1 and Day 2 of the test. $\boldsymbol{D}$, No differences were observed in latency to dark compartment on acquisition day (Day 1; one-way ANOVA; $p>0.05$ ). On test day (Day 2), Ts65Dn mice had a significantly shorter latency to enter into the dark compartment than WT control groups, indicating cognitive impairments. In contrast, GLP-1 (9-36) treatment significantly increased latency to the dark compartment in Ts65Dn mice, indicating improved cognitive function. None of the WT mice treated with GLP-1 (9-36) entered the dark compartment on testing day. (WT+ Saline: $n=7$; Ts65Dn + Saline: $n=3$; WT + GLP-1 (9-36): $n=9$; and Ts65Dn + GLP-1 (9-36): $n=7)$. One-way repeated-measures ANOVA with Tukey's post hoc tests; $* p<0.05, * * p<0.01, * * * p<0.001, * * * * p<0.0001$.

mild foot shock (0.2 $\mathrm{mA}$ for $1 \mathrm{~s})$ on entering the dark chamber; mice from all groups exhibited similar latency to enter the dark chamber on day 1 (Fig. $5 D$ ). On the test day (Day 2), WT mice treated with saline or GLP-1 (9-36) were averse to enter the dark chamber (long latency), indicating normal cognition. Compared with WT mice, the latency to enter the dark chamber was much shorter in salinetreated Ts65Dn mice, indicating cognitive impairment (WT+saline vs Ts65Dn+saline: $p=0.0033$; WT + GLP-1 (9-36) vs Ts65Dn+saline: $p=0.0007$; Fig. $5 D$ ). Importantly, Ts65Dn mice treated with GLP-1 (9-36) displayed improved cognition, as indicated by a significantly longer latency entering the dark chamber, compared with salinetreated group (Ts65Dn+saline vs Ts65Dn+GLP-1 (9-36): $p=0.0455$; Fig. $5 D$ ). Together, these data indicate that GLP-1 (9-36) treatment can rescue the cognitive deficits in aged, Ts65Dn DS model mice.

\section{Discussion}

In the current study, we have shown that GLP-1 (9-36), a natural peptide and the primary cleavage product of the incretin hormone GLP-1 (7-36), ameliorates cognitive deficits and synaptic plasticity impairments in a mouse model of DS. With regards to potential molecular/cellular mechanisms, we found that GLP-1 (9-36) treatment decreased the DS-associated elevated mitochondrial super- oxide, a major ROS that is linked to memory impairments and synaptic failure (Massaad and Klann, 2011; Guo et al., 2017). We also observed that GLP-1 (9-36) treatment led to increased mature dendritc spines in hippocampus. Together, these findings demonstrate that GLP-1 (9-36) may exert beneficial effects on the molecular mechanisms underlying impairments of memory and synaptic plasticity in DS.

This is the first study we are aware of that has characterized dendritic spine morphology in Ts65Dn mouse model of DS. Spines are dynamic structures whose morphologic structure is directly related to function (Berry and Nedivi, 2017), representing an essential mechanism underlying memory and synaptic plasticity. Immature spines are highly dynamic structures that have little function in synaptic transmission but are essential in initiating contact with nearby axons to form synaptic connections (Lohmann et al., 2005). Furthermore, synaptic weakening induced by long-term depression destabilizes and eliminates existing spines (i.e., increases immature spine density; Nagerl et al., 2004; Zhou et al., 2004). Our findings that DS model mice have increased immature spine density are in line with previous work demonstrating that DS model mice have increased GABAergic innervation to the hippocampus (Mojabi et al., 2016). Conversely, mature 
spines form stable connections with presynaptic terminals, and are highly sensitive to glutamatergic transmission (Zito et al., 2009; Berry and Nedivi, 2017). Previous studies have shown that excitatory, glutamatergic transmission increases spine volume and stabilizes newlyformed spines (i.e., increases mature spine density; Lang et al., 2004; Kopec et al., 2006; Zito et al., 2009). The spine's ability to alter their morphology in response to increased or decreased synaptic activity has led some to categorize immature spines as "learning" spines, and mature spines as "memory" spines (Bourne and Harris, 2007). The increased immature spine density in salinetreated Ts65Dn mice may explain their memory impairments. Thus, the shift in spine composition (mature $\gg$ immature) observed in GLP-1 (9-36)-treated Ts65Dn mice may provide a mechanistic explanation for their improved memory and synaptic plasticity.

That the alterations in dendritic spine morphology were associated with decreased mitochondrial oxidative stress with GLP-1 (9-36) treatment is especially interesting. Increased neuronal oxidative stress is a pathologic hallmark of DS and is associated with aging and age-related neurodegenerative diseases (Zana et al., 2007; Dumont et al., 2009; Ma et al., 2011; Massaad and Klann, 2011; Zis et al., 2012; Wang et al., 2014; Panel et al., 2018). AD model mice have elevated mitochondrial superoxide production and impaired memory and synaptic plasiticity (Ma et al., 2012). The association beetween oxidative stress and dendritic spine morphology remains elusive. One study found that a single dose of cranial irradiation, which causes a persistent increase in ROS, caused significantly decreased immature spines and decreased mature spines (Chakraborti et al., 2012). Another study showed that rats with excessive neuronal ROS had a low mature spine density, which was restored with antioxidant treatment (Dos Reis et al., 2013). In the context of our own work, these studies demonstrate a possible causative relationship between excessive ROS and dendritic spine morphology in DS. Meanwhile, future studies are warranted to determine the detailed molecular mechanisms through which oxidative stress interfers with spine maturation in DS.

Currently, there are no effective pharmacological therapies capable of improving cognition in DS patients. We are excited by the findings that GLP-1 (9-36) treatment is able to correct aberrant cognition and synatpic plasticity in the DS model mice. Moreover, the observation that DS-associated increased levels mitochondrial superoxide is blunted by GLP-1 (9-36) treatment agrees with a body of evidence linking mitochondrial ROS to aging-related cognitive and synatpic pathology (Massaad and Klann, 2011; Wang et al., 2014; Guo et al., 2017). Previous studies have attempted to improve cognitive decline in DS patients with antioxidant treatment. Although preclinical studies have found success, they have yet to prove effective in clinical trials (Ani et al., 2000; Lott et al., 2011; Sano et al., 2016). These clinical trials have attempted to improve cognition through either nutritional supplementation or with traditional ROS scavengers such as $\alpha$-tocopherol (vitamin E; Ani et al., 2000; Lott et al., 2011;
Sano et al., 2016). A potential problem with this approach is that it only prevents ROS from oxidizing cellular components, but does nothing to prevent the excessive ROS genesis. Conversely, as we and others have shown, GLP-1 (9-36) protects against oxidative stress and decreased ROS production. It has also been shown to decrease oxidative stress in animal models of cognitive disease, known to have increased ROS production (Ban et al., 2010; Ma et al., 2012; Giacco et al., 2015). Therefore our findings here, in conjuction with previous studies (Ma et al., 2012), suggest that the natural peptide and GLP-1 cleavage product GLP-1 (9-36) has therapeutic potential to improve cognition in DS and other neuronal diseases associated with excessive mitochondrial ROS.

\section{References}

Ani C, Grantham-McGregor S, Muller D (2000) Nutritional supplementation in Down syndrome: theoretical considerations and current status. Dev Med Child Neurol 42:207-213.

Baggio LLD, Drucker DJ (2007) Biology of incretins: GLP-1 and GIP. Gastroenterology 132:2131-2157.

Ban KK, Kim KH, Cho CK, Sauvé M, Diamandis EP, Backx PH, Drucker DJ, Husain M (2010) Glucagon-like peptide (GLP)-1(936)amide-mediated cytoprotection is blocked by exendin(9-39) yet does not require the known GLP-1 receptor. Endocrinology 151: 1520-1531.

Bayen E, Possin KL, Chen Y, Cleret de Langavant L, Yaffe K (2018) Prevalence of aging, dementia, and multimorbidity in older adults with Down syndrome. JAMA Neurol 75:1399-1406.

Berry KP, Nedivi E (2017) Spine dynamics: are they all the same? Neuron 96:43-55.

Bourne J, Harris KM (2007) Do thin spines learn to be mushroom spines that remember? Curr Opin Neurobiol 17:381-386.

Chakraborti A, Allen A, Allen B, Rosi S, Fike JR (2012) Cranial irradiation alters dendritic spine density and morphology in the hippocampus. PLoS One 7:e40844.

Costa AC, Scott-McKean JJ (2013) Prospects for improving brain function in individuals with Down syndrome. CNS Drugs 27:679702.

Day SM, Yang W, Ewin S, Zhou X, Ma T (2017) Glucagon-like peptide-1 cleavage product GLP-1 (9-36) amide enhances hippocampal long-term synaptic plasticity in correlation with suppression of Kv4.2 expression and eEF2 phosphorylation. Hippocampus 27:1264-1274.

Deacon CF, Johnsen AH, Holst JJ (1995) Degradation of glucagonlike peptide- 1 by human plasma in vitro yields an $\mathrm{N}$-terminally truncated peptide that is a major endogenous metabolite in vivo. $J$ Clin Endocrinol Metab 80:952-957.

Dierssen M (2012) Down syndrome: the brain in trisomic mode. Nat Rev Neurosci 13:844-858.

Dos Reis EA, Rieger E, de Souza SS, Rasia-Filho AA, Wannmacher CM (2013) Effects of a co-treatment with pyruvate and creatine on dendritic spines in rat hippocampus and posterodorsal medial amygdala in a phenylketonuria animal model. Metab Brain Dis 28:509-517.

Drucker DJ (2001) Minireview: the glucagon-like peptides. Endocrinology 142:521-527.

Dumont M, Wille E, Stack C, Calingasan NY, Beal MF, Lin MT (2009) Reduction of oxidative stress, amyloid deposition, and memory deficit by manganese superoxide dismutase overexpression in a transgenic mouse model of Alzheimer's disease. Faseb J 23: 2459-2466.

Faizi M, Bader PL, Tun C, Encarnacion A, Kleschevnikov A, Belichenko P, Saw N, Priestley M, Tsien RW, Mobley WC, Shamloo M (2011) Comprehensive behavioral phenotyping of Ts65Dn mouse model of Down syndrome: activation of $\beta 1$-adrenergic receptor by 
xamoterol as a potential cognitive enhancer. Neurobiol Dis 43: 397-413.

Giacco F, Du X, Carratú A, Gerfen GJ, D’Apolito M, Giardino I, Rasola A, Marin O, Divakaruni AS, Murphy AN, Shah MS, Brownlee M (2015) GLP-1 cleavage product reverses persistent ROS generation after transient hyperglycemia by disrupting an ROSgenerating feedback loop. Diabetes 64:3273-3284.

Guo L, Tian J, Du H (2017) Mitochondrial dysfunction and synaptic transmission failure in Alzheimer's disease. J Alzheimers Dis 57: 1071-1086.

Hansen L, Deacon CF, Orskov C, Holst JJ (1999) Glucagon-like peptide-1-(7-36)amide is transformed to glucagon-like peptide-1(9-36)amide by dipeptidyl peptidase IV in the capillaries supplying the $L$ cells of the porcine intestine. Endocrinology 140:5356-5363.

Head E, Lott IT, Wilcock DM, Lemere CA (2016) Aging in Down Syndrome and the development of Alzheimer's disease neuropathology. Curr Alzheimer Res 13:18-29.

Hering H, Sheng M (2001) Dendritic spines: structure, dynamics and regulation. Nat Rev Neurosci 2:880-888.

Ishii T, Takanashi Y, Sugita K, Miyazawa M, Yanagihara R, Yasuda K, Onouchi H, Kawabe N, Nakata M, Yamamoto Y, Hartman PS, Ishii $N$ (2017) Endogenous reactive oxygen species cause astrocyte defects and neuronal dysfunctions in the hippocampus: a new model for aging brain. Aging Cell 16:39-51.

Kandel ER, Dudai Y, Mayford MR (2014) The molecular and systems biology of memory. Cell 157:163-186.

Katz B, Miledi R (1968) The role of calcium in neuromuscular facilitation. J Physiol 195:481-492.

Klann E, Dever TE (2004) Biochemical mechanisms for translational regulation in synaptic plasticity. Nat Rev Neurosci 5:931-942.

Kleschevnikov AM, Belichenko PV, Faizi M, Jacobs LF, Htun K, Shamloo M, Mobley WC (2012) Deficits in cognition and synaptic plasticity in a mouse model of Down syndrome ameliorated by GABAB receptor antagonists. J Neurosci 32:9217-9227.

Kleschevnikov AM, Belichenko PV, Villar AJ, Epstein CJ, Malenka RC, Mobley WC (2004) Hippocampal long-term potentiation suppressed by increased inhibition in the Ts65Dn mouse, a genetic model of Down syndrome. J Neurosci 24:8153-8160.

Knudsen LB, Pridal L (1996) Glucagon-like peptide-1-(9-36) amide is a major metabolite of glucagon-like peptide-1-(7-36) amide after in vivo administration to dogs, and it acts as an antagonist on the pancreatic receptor. Eur J Pharmacol 318:429-435.

Kopec CD, Li B, Wei W, Boehm J, Malinow R (2006) Glutamate receptor exocytosis and spine enlargement during chemically induced long-term potentiation. J Neurosci 26:2000-2009.

Kuc RE, Maguire JJ, Siew K, Patel S, Derksen DR, Margaret Jackson V, O'Shaughnessey KM, Davenport AP (2014) Characterization of [(1)(2)(5)I]GLP-1(9-36), a novel radiolabeled analog of the major metabolite of glucagon-like peptide 1 to a receptor distinct from GLP1-R and function of the peptide in murine aorta. Life Sci 102:134-138.

Lana-Elola E, Watson-Scales SD, Fisher EM, Tybulewicz VL (2011) Down syndrome: searching for the genetic culprits. Dis Model Mech 4:586-595.

Lang C, Barco A, Zablow L, Kandel ER, Siegelbaum SA, Zakharenko SS (2004) Transient expansion of synaptically connected dendritic spines upon induction of hippocampal long-term potentiation. Proc Natl Acad Sci U S A 101:16665-16670.

Lin MT, Beal MF (2006) Mitochondrial dysfunction and oxidative stress in neurodegenerative diseases. Nature 443:787-795.

Lohmann C, Finski A, Bonhoeffer T (2005) Local calcium transients regulate the spontaneous motility of dendritic filopodia. Nat Neurosci 8:305-312.

Lott IT (2012) Neurological phenotypes for Down syndrome across the life span. Prog Brain Res 197:101-121.

Lott IT, Dierssen M (2010) Cognitive deficits and associated neurological complications in individuals with Down's syndrome. Lancet Neurol 9:623-633.

Lott IT, Doran E, Nguyen VQ, Tournay A, Head E, Gillen DL (2011) Down syndrome and dementia: a randomized, controlled trial of antioxidant supplementation. Am J Med Genet A 155A:19391948.

Ma T, Du X, Pick JE, Sui G, Brownlee M, Klann E (2012) Glucagonlike peptide-1 cleavage product GLP-1 (9-36) amide rescues synaptic plasticity and memory deficits in Alzheimer's disease model mice. J Neurosci 32:13701-13708.

Ma TH, Hoeffer CA, Wong H, Massaad CA, Zhou P, ladecola C, Murphy MP, Pautler RG, Klann E (2011) Amyloid beta-induced impairments in hippocampal synaptic plasticity are rescued by decreasing mitochondrial superoxide. J Neurosci 31:5589-5595.

Macklin L, Griffith C, Cai Y, Rose G, Yan X, Patrylo P (2017) Glucose tolerance and insulin sensitivity are impaired in APP/PS1 transgenic mice prior to amyloid plaque pathogenesis and cognitive decline. Exp Gerontol 88:9-18.

Massaad CA, Klann E (2011) Reactive oxygen species in the regulation of synaptic plasticity and memory. Antioxid Redox Signal 14:2013-2054.

Mégarbané A, Ravel A, Mircher C, Sturtz F, Grattau Y, Rethoré MO, Delabar JM, Mobley WC (2009) The 50th anniversary of the discovery of trisomy 21: the past, present, and future of research and treatment of Down syndrome. Genet Med 11:611-616.

Mojabi FS, Fahimi A, Moghadam S, Moghadam S, Windy McNerneny M, Ponnusamy R, Kleschevnikov A, Mobley WC, Salehi A (2016) GABAergic hyperinnervation of dentate granule cells in the Ts65Dn mouse model of Down syndrome: exploring the role of App. Hippocampus 26:1641-1654.

Nagerl UV, Eberhorn N, Cambridge SB, Bonhoeffer T (2004) Bidirectional activity-dependent morphological plasticity in hippocampal neurons. Neuron 44:759-767.

Nelson LD, Siddarth P, Kepe V, Scheibel KE, Huang SC, Barrio JR, Small GW (2011) Positron emission tomography of brain betaamyloid and tau levels in adults with Down syndrome. Arch Neurol 68:768-774.

Nikolaidis LA, Elahi D, Shen YT, Shannon RP (2005) Active metabolite of GLP-1 mediates myocardial glucose uptake and improves left ventricular performance in conscious dogs with dilated cardiomyopathy. Am J Physiol Heart Circ Physiol 289:H2401-H2408.

Pagano GC, Castello G (2012) Oxidative stress and mitochondrial dysfunction in Down syndrome. Adv Exp Med Biol 724:291-299.

Panel M, Ghaleh B, Morin D (2018) Mitochondria and aging: a role for the mitochondrial transition pore?. Aging Cell 17:e12793.

Patterson D (2009) Molecular genetic analysis of Down syndrome. Hum Genet 126:195-214.

Patterson D, Costa AC (2005) Down syndrome and genetics: a case of linked histories. Nat Rev Genet 6:137-147.

Risher WC, Ustunkaya T, Singh Alvarado J, Eroglu C (2014) Rapid Golgi analysis method for efficient and unbiased classification of dendritic spines. PLoS One 9:e107591.

Sala C, Segal M (2014) Dendritic spines: the locus of structural and functional plasticity. Physiol Rev 94:141-188.

Sano M, Aisen PS, Andrews HF, Tsai WY, Lai F, Dalton AJ; International Down Syndrome and Alzheimer's Disease Consortium (2016) Vitamin E in aging persons with Down syndrome: a randomized, placebo-controlled clinical trial. Neurology 86:2071-2076.

Shi Y, Sun D (2012) Neurobehavioral assessments of focal cerebral ischemia: cognitive deficit. In: Animal models of acute neurological injuries ii: injury and mechanistic assessments, Vol 2 (Chen J, Xu XM, Xu Z, Zhang J eds), pp 157-162. Totowa, NJ: Humana.

Vahl TP, Paty BW, Fuller BD, Prigeon RL, D'Alessio DA (2003) Effects of GLP-1-(7-36)NH2, GLP-1-(7-37), and GLP-1- (9-36)NH2 on intravenous glucose tolerance and glucose-induced insulin secretion in healthy humans. J Clin Endocrinol Metab 88:1772-1779.

Wang X, Wang W, Li L, Perry G, Lee HG, Zhu X (2014) Oxidative stress and mitochondrial dysfunction in Alzheimer's disease. Biochim Biophys Acta 1842:1240-1247.

Wong H, Levenga J, Cain P, Rothermel B, Klann E, Hoeffer C (2015) RCAN1 overexpression promotes age-dependent mitochondrial 
dysregulation related to neurodegeneration in Alzheimer's disease. Acta Neuropathol 130:829-843.

Zana M, Janka Z, Kálmán J (2007) Oxidative stress: a bridge between Down's syndrome and Alzheimer's disease. Neurobiol Aging 28: 648-676.

Zhou Q, Homma KJ, Poo MM (2004) Shrinkage of dendritic spines associated with long-term depression of hippocampal synapses. Neuron 44:749-757.
Zigman WB (2013) Atypical aging in Down syndrome. Dev Disabil Res Rev 18:51-67.

Zis P, Dickinson M, Shende S, Walker Z, Strydom A (2012) Oxidative stress and memory decline in adults with Down syndrome: longitudinal study. J Alzheimers Dis 31:277-283.

Zito K, Scheuss V, Knott G, Hill T, Svoboda K (2009) Rapid functional maturation of nascent dendritic spines. Neuron 61: 247-258. 